Highway safety

\section{Reflections on the highway safety field}

A F Williams

\section{Patricia F Waller Memorial Lecture Chapel Hill, North Carolina, 28 April 2004}

to is a great honor to have been invited to give the inaugural Patricia F Waller memorial lecture. Certainly any reflections on this field would have to note Pat's many significant contributions over several decades. I will mention several, as I tell you what I think about the status of the highway safety field, based on my own 30+ years of experience.

Pat and I served together on various committees. The most recent was a National Academy of Sciences committee assembled to assess the status of the injury control field. Motor vehicle injury control was determined to be the "show horse" of the field, as evidenced by this quote from the committee report: "Over the past three decades, dramatic progress has been made in reducing motor vehicle injuries by understanding the factors that increase the risk of injury, designing interventions to reduce these risks, and implementing and evaluating a wide array of interventions". ${ }^{1}$

I am going to darken this rosy assessment somewhat because not all is well with the highway safety situation in the United States. To some extent this is because of factors that have always been with us, and to some extent it is because of more recent developments.

First, the field is held back by woeful underfunding. We don't pay very much attention to the highway safety problem, which is evident when you "follow the money". In 2004 the United States federal research budget for the National Cancer Institute was $\$ 3$ billion, for the National Heart, Lung, and Blood Institute \$2.3 billion, and for highway safety research (the National Highway Traffic Safety Administration and the Federal Highway Administration) \$164 million. These are huge differentials, even though in terms of adjusted years of life lost before age 75 cancer and heart disease are each only $2-3$ times that of motor vehicle injuries. The National Institute of Dental Research received \$349 million for research in 2004. It is ridiculous that this is more than twice what we spend for highway safety research.

Regrettably, we waste a lot of the money we do get on ineffective programs that are embedded in our society and have been so for a long time. In 1964 William Haddon, an early pioneer, noted that "countermeasures are frequently adopted without adequate evidence of their effectiveness.... For example, such measures as motor vehicle inspections, speed laws, licensing requirements, and public information programs are often adopted on the attempt to assess... their effectiveness. This is in sharp contrast with the introduction of measures for the alleviation of other public health problems (p 5)".

There are many examples of wasteful public information programs. A recent example is the "Stop Red Light Running Campaign", which used federal and other money to "raise awareness about the dangerous and costly problem of running red lights". But how many people don't know you shouldn't run red lights? Even my 5 year old grandson knows this. This "public information" exercise misses the real issue in any case. We all pretty much know what we are supposed to do and not do on the highways. What we do, however, is another matter, often unrelated to knowledge about the appropriate behaviors.

Some programs actually undercut the goal of safety. For example, in some states we allow traffic violators to go to traffic schools. Yet we know from research these are ineffective and allow violators to avoid licensing penalties, which we know from research are effective. ${ }^{3}$ Another example is that for decades we licensed young people in a way that, as Pat said, "violates almost everything we know about learning". We are all familiar with the tragic results of that policy.

Public attention to highway safety, to the extent it's there, wanders from issue to issue. We focused on alcohol impaired driving in the 1980s, which was appropriate. Then we shifted attention to the "aggressive" driver, and now we are in the era of the "distracted driver". That is, we have shifted from important issues to lesser issues, if not pseudo issues. Some of this is media basis of 'common sense', with little driven. For example, we had outbreaks of concern about "aggressive" drivers in the 1970s and 1980s in parts of the country, following some spectacular "road rage" incidents, and then after a while attention to this issue faded.

All of this would not matter so much except that we're not doing so well recently. Motor vehicle deaths in the United States have increased each year since 1998. Death rates based on vehicle registrations, miles driven, and population have basically leveled off after having declined considerably in the 1970s and 1980s. Canada, Australia, and most northern European nations have had greater declines in their motor vehicle death rates in the past decade, and the United States is no longer in the top group.

We were pretty insular in the 1970s and 1980s, but there is much more globalization now and increased interaction worldwide. There is a tendency to think we are unique, but a lot of the trends we observe in the United States also are happening elsewhere. The substantial decline in the 1980s in alcohol impaired driving and its consequences was experienced in many countries. These common trends bring with them some mysteries about how and why progress is made and about the measures we think were important in producing gains. Raising the minimum alcohol purchase age to 21 in the United States is considered to be pivotal in reducing alcohol impaired driving crashes among 16-20 year olds. Yet in Canada, where the minimum purchase age wasn't raised, there was as much or more decline involving drivers of these ages during the same time period. The importance of citizen activist groups such as MADD [Mothers Against Drunk Driving] in energizing the 1980s movement is widely acknowledged. Yet in Australia and European countries that had similar reductions during this period, equivalent groups didn't exist. I'm not saying that MADD and the minimum purchase age of 21 weren't important factors in United States, only that apparently you can get to the same place in different ways.

We have made substantial progress in reducing motor vehicle injuries in the United States, but clearly we have much to do to move forward.

Pat and I shared several attributes. Both of us came from social science backgrounds. In the early days, no one was trained in injury control. Bill Haddon talked about most of the early research being done by "dedicated but irrelevantly trained professionals". I backed into the field, like many others. When I started, many of my contemporaries were social scientists, often 
psychologists, often experimental psychologists such as B J Campbell, the first director of the North Carolina Highway Safety Research Center. We didn't have injury control training, but we had in common strong research design backgrounds. Science in the highway safety field was introduced largely by social scientists who came into the field in the early 1970s or before.

Social scientists brought some outside perspective to the highway safety field. One aspect of this involved recognition that motor vehicle injuries are a low priority and why this is so. We know from risk perception research that in very familiar activities there is a tendency to minimize the probability of bad outcomes. People underestimate risks that are supposed to be under their control. ${ }^{4}$ This sense of subjective immunity is bolstered by people's beliefs that their driving skills are superior. Most think they are above average drivers. It's the mythical "other driver" who is the problem, and safety messages are for him or her, not us.

These zones of immunity we create around ourselves beget public apathy or indifference about the problem. People see motor vehicle injuries as a societal problem but one that does not particularly affect them. As a society we pretty much accept the substantial toll of deaths and injuries we incur each year.

When do you ever hear politicians debate highway safety issues? A few years ago I went to a presentation by a candidate for the US House of Representatives and asked a question about highway safety. He responded that no one had ever before asked him a question on this topic. It seems to be under the radar screen, and perhaps this explains why there is so little political will to apply more vigorously some of the things we know from research will work to reduce highway safety problems.

Neglect of this problem is nothing new. Bill Haddon in 1964 delineated all the standard reasons why we devalue safety, even adding some speculative thoughts: “...accidents may conceivably provide our society with satisfactions related to those derived from human sacrifice, Roman circuses, public execu-

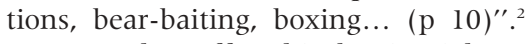
Most people scoff at this, but it might at least give you something to think about the next time you are in a rubbernecking traffic jam, where traffic essentially comes to a halt while drivers crane their necks to observe a crash scene on the other side of the road.

Given this social context, how do you motivate people to do the right thing on the highways? My social psychology background and knowledge of behavior change techniques were of limited usefulness in this regard, because the situation is that people already have ingrained habits, they think safety messages aren't for them but for other drivers, and the behaviors we want to affect are at the extreme end of the active-passive dimension, that is, they have to be done every time you drive a car. I am certain that I could take you in this audience and randomly divide you into treatment and control groups and get many in the treatment group to do a one time behavior such as getting a flu shot. However, for something like seat belt use you have to have an enduring influence, and that's not easy.

To motivate people to do the right thing on the highways, we have learned that you have to use law enforcement and the threat of penalties. You also have to look at other options. Psychologists want to fix people, but you also can fix vehicles and fix the environment in ways that facilitate crash avoidance or improve crashworthiness. Pat was comfortable with this broader public health approach, as her writings reflect.

Another perspective is that motor vehicle injuries are the result of a safety/mobility trade-off. We could reduce injuries to zero if we wanted to, and the question for societies is where to strike the balance between mobility and safety. This is not like diseases, where there is only downside. We gain much from the mobility vehicles provide.

Researchers don't decide how we balance safety and mobility. Our function is to conduct objective scientific research that specifies the consequences of policies or laws or programs, and to get that information injected into public debate on these issues. Of course, our public health orientation means we want things that work to be implemented, so most researchers in one way or another become advocates for policies that work. This can be a difficult dual role, one that Pat played about as well as anyone in the field. It's a balancing act.

To move forward, we need to take on the tough issues and be smart about how we approach them.

Law enforcement is critical, which means police are a key group. We need a better understanding of police culture. When we were conducting a "Click It or Ticket" pilot project in Elizabeth City, North Carolina, a police officer said to me, "Don't ever let anyone tell you that police don't like to enforce laws. That's why we became policemen". But, he noted, we need political permission to do so. Politicians, in turn, do what the public wants or will support. So you have this interplay among the three Ps: public, politicians, and police. The police have many competing demands and limited resources. They also have their own attitudes about various highway safety issues. Within this context, I don't think we know enough about the factors that influence highway safety enforcement or about the attitudes and motivations of the police that influence what they do regardless of departmental policies.

\section{TRAFFIC ENGINEERING CHANGES}

There is a gold mine of opportunity here that we don't take sufficient advantage of. That is, instead of telling drivers what to do, you can change the environment in ways that change driver behavior and reduce crashes. At the Insurance Institute we have used a statistical technique to identify particular types of crashes that cluster at specific intersections. ${ }^{6}$ Visiting these sites, it's usually apparent what the problem is, and we have several examples where instituting necessary changes, often inexpensive, virtually eliminates the crash type.

\section{OLDER DRIVERS}

How can we best address the safety/ mobility trade-off with this growing group? We want to maximize both safety and mobility for our aging population. The solutions are not easy to come by, but we have to try to find them.

\section{DRIVER EDUCATION}

It doesn't work as intended-that is, to produce safer drivers. Why would you expect it to? Pat Waller put her finger on this way back in 1977, in a very gentle way, when she wrote, "Probably no other high school course is evaluated on the same terms as driver education. The English teacher is not evaluated on the basis of the correspondence his students write in later life. The math teacher is not evaluated on the basis of how well his students balance their checkbooks. Yet the driver education teacher is held responsible for the subsequent driver records accumulated by his students. Should the driver education teacher be responsible only for whether the student can drive adequately or whether he actually does drive in this manner? His subsequent performance is the result of many factors, such as peer influence, home pressures, and the student's own personality, all of which are beyond the influence or control of the driver education teacher". ${ }^{7}$

Yet the public loves driver education, which receives overwhelming support as a preferred way to reduce the young 
driver problem. Can we somehow make that a reality?

There is a worldwide trend to maximize the amount of experience gained by young beginners before licensure. In the United States we approach this through longer mandatory learner periods as part of graduated licensing systems. An interesting approach is being tried in Australia, combining professional instructors and parents during the learning period. The Royal Automobile Club of Victoria has devised a program that starts off with an initial 45-60 minute driving session, during which a parent joins the learner and instructor, and throughout the learner period provides for interaction between the instructor and parents. The intention is to combine professional instruction in driving skills with maximum supervised practice, facilitated by parents guided by professionals. Whether or not this merger will have benefits isn't yet known, but it has promise.

\section{SPEEDING}

We don't take the consequences of speeding very seriously. Brian O'Neill, the president of the Insurance Institute, said recently, "Attitudes have changed toward alcohol and driving but not toward speeding. They are equally egregious behaviors because the outcomes are the same. But public policy does not recognize this".

At the least we need to be smarter about speed limits and quit thinking we can raise them without negative consequences. There has been talk in some states about further increasing speed limits. The claims are the same as in the past: So many people exceed speed limits that we are creating a nation of lawbreakers, roads were designed for higher speeds, and we should raise the limits to account for these factors. An engineering maxim is that speed limits ought to be set at the 85 th percentile speed. The research shows very clearly that what happens when you raise speed limits on higher speed roads is that travel speeds increase and a new 85 th percentile emerges. ${ }^{8}$ So what are we supposed to do, keep raising the limits until we eventually reach a ceiling on speeds? By the flawed 85th percentile logic, that's the prescription.

\section{ALCOHOL IMPAIRED DRIVING}

There's a heavily promoted view that the part of the problem we haven't solved involves so-called "hard core" drinking drivers, the multiple offenders, those with very high blood alcohol concentrations (BACs). In fact, the problem was reduced to about the same extent in the 1980s and early 1990s among all BAC categories, including those at the extreme $(0.25 \%$ BAC and more). Research also suggests that not all the drivers at high BACs are part of the hard core, as is commonly assumed. ${ }^{9}$ The obsession with hard core drinking drivers has obscured the fact that we have multiple targets and don't know enough about the drinking histories and predisposing factors of the various groups who contribute to the problem.

\section{YOUNG DRIVERS}

Much effort has gone into convincing states to enact night driving restrictions for beginners, on the basis that the risk is much higher than during the day. However, night-time exposure is quite low, so even with the increased risk not many crashes occur between midnight and $6 \mathrm{am}$, the most popular time for the night restrictions. In 1995, before most of the restrictions were enacted, only $4 \%$ of police-reported crashes of 16-17 year olds and $14 \%$ of their fatal crashes took place during these hours. The bulk of crashes take place during the daytime and early evening hours, with peaks just before school (7-8 am) and just after (3-4 pm). Daytime driving may be less risky on a per mile basis, but that's where the action is in terms of numbers, and we can't afford to ignore school transportation polices and other policies such as passenger restrictions that potentially affect these crashes.

The overriding question is, can we get more attention to the highway safety problem? We got it once, in the late 1960s after yearly deaths had soared from around 36000 in 1960 to more then 50000 . We don't want to get it that way again.

Another question is whether we can get more focus on the important problems in the highway safety field. When you look at the literature on social movements, you learn that social problems have careers, things run in cycles, and the public can't pay or usually doesn't pay attention to more than one issue at a time. This is the so called "public arenas" model of social movements. ${ }^{10}$ MADD has been saying for the past few years that it's time to get mad all over again, but you don't create or recreate social movements just by calling for them. We don't know or can't control whatever secular forces precipitate social movements.

A challenge is that motor vehicle deaths happen primarily in ones and twos. We know that on average more than 100 people are killed each day, but we don't have the daily toll until many months later. People who study the effects of death on society make a distinction between statistical deaths and identified deaths, that is, those that resonate. ${ }^{11}$ Motor vehicle deaths are statistical deaths, part of the fabric, except occasionally when a spectacular crash draws attention.

We in the field try to take advantage of these unfortunate deaths to generate public and political interest in specific legislation. But what we really want is a societal shift in response to the motor vehicle injury problem. Let me introduce you then to Vision Zero, a concept that originated in Sweden and was bought into by the Swedish government in 1997. ${ }^{12}$ The ultimate goal is no fatal or serious injuries on the roads, that is, to avoid trade-offs between fatalities and benefits such as faster travel. Of course, it isn't possible to reduce fatalities to zero, but this is enlightened public policy and stands in contrast to a lot of what I said earlier about the motor vehicle injury problem being one that the public ignores or implicitly accepts. Vision Zero reminds us that we don't have to accept the trade-off between safety and mobility, at least to the extent we have.

I view this as a wake-up call, a call for us in the highway safety field to be passionate about what we do, keeping in mind that a lot of people are dying or being maimed needlessly, including children, teens, and young adults just getting started in their lives. Instead of public apathy, there should be public outcry.

We need to believe that by doing good research and by being good spokespeople for our research, we can make a difference.

Pat Waller had this passion. If I had to pick out the one quality I will most remember Pat for, it would be that she was very, very serious about the highway safety problem and about promoting ways to address it. She commanded great respect because of that and made a difference because of it.

That is my inspiration from Pat, and whether you are in the highway safety field or some other field I hope it may be yours.

\section{ACKNOWLEDGEMENTS}

This work was supported by the Insurance Institute for Highway Safety.

Injury Prevention 2004;10:330-333.

doi: 10.1136/ip.2004.006528

Correspondence to: Dr Allan F Williams, Insurance Institute for Highway Safety, 1005 North Glebe Road, Arlington, VA 22201, USA; awilliams@iihs.org

\section{REFERENCES}

1 Institute of Medicine. Reducing the burden of injury. Washington, DC: National Academy Press, 1999. 
2 Haddon W Jr, Suchman EA, Klein D. Accident research: methods and approaches. New York NY: Harper \& Row, 1964.

3 Peck RC, Gebers MA. The traffic safety impact of TVS citation dismissals. Report No 133 Sacramento, CA: California Department of Motor Vehicles, 1991.

4 Douglas M. Risk acceptability according to the social sciences. New York, NY: Russell Sage Foundation, 1985

5 Williams AF. Views of US drivers about driving safety. J Safety Res 2003:34:491-4.
6 Insurance Institute for Highway Safety. Traffic engineering approaches to reduce crashes on urban arterial roads. Arlington, VA: IIHS 2000.

7 Waller PF. Driver education: where does it belong? J Traffic Safety Educ 1977;25 7-9.

8 Freedman M, Esterlitz JR. Effect of the 65-mph speed limit on speeds in three states. Transportation Research Record 1281:51-62. Washington, DC: Transportation Research Board, 1990.
9 Baker SP, Braver ER, Chen L-H, et al. Drinking histories of fatally injured drivers. Inj Prev 2002;8:221-6.

10 Hilgartner S, Bosk C. The rise and fall of social problems: a public arenas model. Am J Sociol 1988;94:53-78.

11 Jenni KE, Loewenstein G. Explaining the "identifiable victim effect". J Risk Uncertain 1997; 14:235-57.

12 Tingvall C, Haworth N. Vision zero: an ethical approach to safety and mobility. Victoria, Australia: Monash University Accident Research Centre, 1999.

\section{Cochrane Injuries Group}

W hat new technologies are available that might cut death rates for road traffic injury and what evidence is available as to their effectiveness? One of the four new reviews from the Cochrane Injuries Group has examined the use of alcohol ignition interlock devices in programmes intended to reduce recidivism among convicted drinkdrivers.

Convicted drink-drivers are sometimes offered the choice of a standard punishment, or for an alcohol ignition interlock to be fitted to their car for a fixed period. To operate a vehicle equipped with an interlock, the driver must first give a breath specimen. If the breath alcohol concentration of the specimen is too high, the vehicle will not start. Our reviewers found 14 studies meeting their inclusion criteria that had been conducted to see whether the interlock stopped drink-drivers from offending again. They included one randomised controlled trial. However, most of the studies were not of high quality. The interlock seems to reduce reoffending, in both first time and repeat offenders, as long as it is still fitted to the vehicle. Sadly, there seems to be no long term benefit after it has been removed. More studies of good quality are needed to confirm these findings. One problem that has emerged is the low percentage of offenders who choose to have an interlock fitted; this makes it difficult to reach firm conclusions about their effectiveness.

Some high tech interventions turn out to be useful in some parts of the world but they may be too expensive to use in those countries that bear the greatest burden of road traffic injury - the developing world. One of the challenges faced by our group is to try to ensure that the majority of our reviews are relevant to the needs of decision makers working with limited resources. The authors of systematic reviews also need to take note of where their included studies took place-usually in high income countries-and consider whether the interventions in question are robust enough to retain their effectiveness in other environments.

We will be more likely to meet these challenges if we involve more people from developing countries in the writing of our reviews. It is, therefore, very encouraging to be able to report that one of our projects now in the pipeline deals with a major cause of injury in developing countries, drowning, and will be written by two Vietnamese reviewers. ${ }^{2}$ They point out that an estimated $97 \%$ of drownings occur in the developing world. The diverse circumstances in which drowning occurs contributes to the challenge of developing effective and appropriate prevention programmes. This review is unusually broad in its scope as the reviewers want to examine all possible ways of reducing the loss of life.

There are of course other systematic reviews on injury prevention also on the way. We have recently published protocols for the following projects: "Home safety education and provision of safety equipment for injury prevention", and "Child-resistant containers in the prevention of childhood poisoning"'.

P I Chinnock

Cochrane Injuries Group; paul.chinnock@|shtm.ac.uk

\section{REFERENCES}

1 Willis C, Lybrand S, Bellamy N. Alcohol ignition interlock programmes for reducing drink driving recidivism. (Cochrane review.) The Cochrane library. Chichester, UK: John Wiley, 2004, Issue 4.

2 Pham CV, Le LC. Interventions for drowning prevention in children and young people. (Protocol for a Cochrane review.) The Cochrane library. Chichester, UK: John Wiley, 2004, Issue 3. 